\title{
Studies on substrate evaluation for mass multiplication of Trichoderma spp. and their plant growth promotion activity in tomato
}

ASHISH KUMAR* AND TARENDRA KUMAR SAHU

Department of Plant Pathology, College of Agriculture, Jawaharlal Nehru Krishi Vishwavidyalaya, REWA (M.P.) INDIA

\section{ARITCLE INFO}

Received : 26.06 .2014

Revised : 11.08 .2014

Accepted : 26.08 .2014

\section{KEY WORDS :}

Trichoderma, Colony forming unit, Mass multiplication, Barnyard millet, Tomato

*Corresponding author: Email: ashishashish2612@gmail.com

\begin{abstract}
The use of micro-organisms that antagonize plant pathogens (biological control) is risk-free when it results in enhancement of resident antagonists and with additional benefit, when it provides the plant growth promotion activity. Ninety per cent of such applications have been carried out with different strains of Trichoderma which have long been recognized as agents for the control of plant disease and for their ability to increase plant growth and development. Due to their antifungal and plant growth promotion properties, many Trichoderma spp. like T. asperellum, T. atroviride, T. harzianum, T. hamatum, T. koningii, T. virens and T. viride are widely used for biocontrol of plant diseases incited by fungal pathogens. In the present investigation, a set of 5 local isolates of Trichoderma harzianum from Madhya Pradesh were used for evaluating their plant growth promotion potential in tomato and it was observed that isolates were having differential inborn capability to provide growth promotion when supplemented as seed and seedling treatment. With the aim of development of commercial formulation for direct use by farmers, five small millet substrates were used and it was observed that barnyard millet maximum supported the colonization of Trichoderma spp. and served as economic source for its multiplication to develop commercial formulation under laboratory conditions.
\end{abstract}

How to view point the article : Kumar, Ashish and Sahu, Tarendra Kumar (2014).Studies on substrate evaluation for mass multiplication of Trichoderma spp. and their plant growth promotion activity in tomato. Internat. J. Plant Protec., 7(2) : 382-388. 